\title{
Extrahepatic Bile Duct Undifferentiated Carcinoma
}

National Cancer Institute

\section{Source}

National Cancer Institute. Extrahepatic Bile Duct Undifferentiated Carcinoma. NCI

Thesaurus. Code C5780.

A carcinoma without evidence of differentiation arising from the extrahepatic bile ducts. 